\begin{tabular}{|c|c|}
\hline Title & Oxidation-resistant multilayer coatings using an anodic al umina layer as a diffusion barrier on y - TiA I substrates \\
\hline Author(s) & Kuranishi, T.; Habazaki, H.; Konno, H. \\
\hline Citation & $\begin{array}{l}\text { Surface and Coatings Technology, 200(7), 2438-2444 } \\
\text { https://doi.org/10.1016/J.surfcoat.2004.08.211 }\end{array}$ \\
\hline Issue Date & $2004-10-12$ \\
\hline Doc URL & http:/hdl.handle.net/2115/984 \\
\hline Type & article (author version) \\
\hline File Information & SCT 200-71.pdf \\
\hline
\end{tabular}

Instructions for use 


\title{
Oxidation-Resistant Multilayer Coatings Using an Anodic Alumina Layer as a Diffusion Barrier on $\gamma$-TiAl Substrates
}

\author{
T. Kuranishi, H. Habazaki* and H. Konno \\ Graduate School of Engineering, Hokkaido University, \\ N13-W8, Kita-ku, Sapporo 060-8628, Japan \\ *Corresponding author: habazaki@eng.hokudai.ac.jp
}


Abstract

Diffusion barrier layers of anodic alumina, introduced between an oxidation-resistant Al-Nb-Cr alloy and $\gamma$-TiAl substrate, have been evaluated using scanning electron microscopy and electron probe microanalysis. Diffusion of titanium to the Al-Nb-Cr coating is obvious when the $\mathrm{Al}-\mathrm{Nb}-\mathrm{Cr}$ alloy coated directly on the TiAl substrate is oxidized at $900^{\circ} \mathrm{C}$ for $168 \mathrm{~h}$. The anodic alumina layer has been introduced by sputter-depositing aluminum and subsequent anodizing of the aluminum layer at a constant current density in $0.01 \mathrm{~mol} \mathrm{dm}^{-3}$ ammonium pentaborate electrolyte at $298 \mathrm{~K}$. Then, the Al-Nb-Cr alloy is further sputter-deposited on the anodized specimens. It is clearly demonstrated that the thin anodic alumina layer, less than $500 \mathrm{~nm}$ thick, suppresses effectively the inter-diffusion between the oxidation-resistant alloy coating and the TiAl substrate, particularly when a thin aluminum layer is remained beneath the anodic alumina. Although microcracks are generated and the substrate is oxidized through the cracked regions for the coatings that contain the metallic aluminum layer, the oxidation of the substrate through the cracks is prevented by pre-oxidation treatment at $800^{\circ} \mathrm{C}$.

Keywords: anodic alumina, titanium aluminides, high temperature oxidation, inter-diffusion, sputter-deposition 


\section{Introduction}

Intermetallic alloys based on $\gamma$-TiAl are of increased interest due to their high mechanical strength at elevated temperatures and their low densities. From these superior properties, these alloys are promising structural materials for aerospace and automotive applications [1-3]. However, their oxidation resistance is limited at elevated temperatures between $750-1000^{\circ} \mathrm{C}$, such that many investigations have been carried out to improve their oxidation resistance. Various third elements, including chlorine, chromium, hafnium, niobium, silicon, silver, tantalum and tungsten, improve the oxidation resistance of TiAl, and the beneficial effects of these alloying elements are summarized by Fergus [4]. Despite the remarkable improvement of the oxidation resistance of $\gamma$-TiAl based alloys by alloying additions, the alloying additions frequently deteriorate their mechanical properties. Another way to improve the oxidation resistance is surface modification, which promotes the formation of highly protective alumina scales. It has been reported that pre-oxidation treatment at low oxygen partial pressure [5-8], sulfidation pretreatments $[9,10]$, pack cementation [11-21] and ion implantation [22-39], as well as oxidation-resistant alloy coatings[12, 40-43], are effective in improving the oxidation resistance. To achieve the long-term stability of the oxidation-resistant coatings, diffusion of titanium in the substrate toward the coatings, which frequently reduces the coating performance against oxidation, must be avoided. Thus, it is preferable to introduce a barrier layer for titanium diffusion between oxidation-resistant coatings and TiAl-based alloy substrates.

Anodizing of high purity aluminum in neutral aqueous electrolytes, including borate electrolytes, results in formation of barrier-type anodic alumina films with uniform thickness [44]. The anodic alumina is generally amorphous and contaminated with species derived from electrolyte anions. The in-depth distribution and concentration of the incorporated electrolyte-derived species are dependent upon the type of the anions [45]. For borate anions, 
they are present in the outer about $40 \%$ of the film thickness when the film growth proceeds at high current efficiency. However, their concentration are generally low, less than 1\% [46], such that anodic oxides formed on aluminum is essentially alumina. Anodic films formed at a constant current density grow almost linearly with increasing electrode potential by high-field ionic transport of both aluminum and oxygen ions [44]. The film growth proceeds under the high electric field of $\sim 1 \times 10^{7} \mathrm{~V} \mathrm{~cm}^{-1}$, such that physical defects introduced in the anodic films must be healed during film growth to sustain the high electric field. Thus, alumina films formed by anodizing are promising barrier layers for diffusion.

In the present study, anodic alumina layers have been formed by anodizing of a thin high purity aluminum layer, sputter-deposited on to $\gamma$-TiAl substrate, in dilute ammonium pentaborate electrolyte. An Al-Nb-Cr alloy layer has been further sputter-deposited as an oxidation-resistant coating. The alumina layer as a diffusion barrier during oxidation in air at $900^{\circ} \mathrm{C}$ has been evaluated mainly by cross-sectional SEM observations and EPMA analysis.

\section{Experimental}

Ti-50 at\% Al alloy ingots of cylindrical shape were prepared by argon-arc melting of a mixture of $99.5 \%$ pure titanium and $99.99 \%$ pure aluminum. The ingots were re-melted several times to make the alloy composition homogeneous. Further homogenization was performed by annealing the ingots in vacuum at $1100^{\circ} \mathrm{C}$ for $24 \mathrm{~h}$. The alloy substrates of approximately $1 \mathrm{~mm}$ thickness were cut off from the ingots, and the surface was ground with a series of SiC papers up to \#1500 and then polished with alumina powders of $1 \mu \mathrm{m}$ in size. X-ray diffraction pattern of the substrate revealed diffraction lines of only $\gamma$-TiAl.

Thin aluminum layers were deposited by dc magnetron sputtering on to the TiAl substrates as well as glass plates for $8 \mathrm{~min}$. The target used was 99.999\% pure aluminum disk of $100 \mathrm{~mm}$ in diameter. Then, the alumina layer was anodized to prescribed cell voltages at a 
constant current density of $50 \mathrm{~A} \mathrm{~m}^{-2}$ in stirred $0.01 \mathrm{~mol} \mathrm{dm}^{-3}$ ammonium pentaborate electrolyte at $25^{\circ} \mathrm{C}$ without current decay. Thickness of the sputter-deposited aluminum layer was estimated by anodizing of the aluminum layer deposited on glass substrate; from the maximum voltage for anodizing, at which aluminum layer was completely anodized, the thickness was determined assuming a formation ratio of $1.2 \mathrm{~nm} \mathrm{~V}^{-1}$ [47] and a Pilling-Bedworth ratio of 1.61 for anodic alumina [48].

Al-21 at\% Nb-10 at\% Cr alloy layers of 5-8 $\mu \mathrm{m}$ thickness was sputter-deposited on to the anodized substrates as well as directly to the alloy substrates for $2-2.5 \mathrm{~h}$. The target consists of $99.999 \%$ pure aluminum disk of $6 \mathrm{~mm}$ in diameter, on the sputter-erosion region of which $99.9 \%$ pure chromium and niobium disks of $20 \mathrm{~mm}$ in diameter were placed symmetrically. To get alloy films of uniform thickness and composition, substrate holders were rotated around the central axis of the chamber as well as their own axes.

Oxidation of the specimens thus prepared was carried out in air at $900^{\circ} \mathrm{C}$ up to $168 \mathrm{~h}$. Since only one side of the each TiAl substrate was coated by the Al-Nb-Cr alloy with and without alumina layer, no kinetic results were obtained during oxidation of the coated specimens. The oxidized specimens were analyzed using X-ray diffraction, field emission-scanning electron microscopy (JEOL JSM-6300F or JSM-6500F), and electron probe microanalysis (JEOL JSM-5410 equipped with Oxford WDX-400).

\section{Results and Discussion}

\subsection{Oxidation of $\gamma$-TiAl}

Fig. 1 shows a scanning electron micrograph of a fracture cross-section of the TiAl alloy specimen oxidized at $900^{\circ} \mathrm{C}$ for $24 \mathrm{~h}$. Rather thick oxide scale of $12 \mu \mathrm{m}$ thickness is formed on the alloy substrate, which appears at the bottom of the micrograph. The scale consists of two layers. The outer layer, $2 \mu \mathrm{m}$ thick, is composed of well-crystallized $\mathrm{TiO}_{2}$ oxides and the 
inner layer, $10 \mu \mathrm{m}$ thick, is a mixture of $\mathrm{TiO}_{2}$ and $\mathrm{Al}_{2} \mathrm{O}_{3}$, as reported previously [49]. The phase identifications have been carried out using EPMA and glancing incidence X-ray diffraction. The X-ray diffraction patterns of the TiAl specimen oxidized at $900^{\circ} \mathrm{C}$, obtained at two incident angles of X-ray ( $\alpha=1$ and $10^{\circ}$ ) are revealed in Fig. 2. In the diffraction pattern obtained at $\alpha=10^{\circ}$, rutile and $\alpha-\mathrm{Al}_{2} \mathrm{O}_{3}$ phases are observed, while only the rutile phase is detected at $\alpha=1^{\circ}$. Thus, the outer layer should consist of the rutile phase. Although $\alpha-\mathrm{Al}_{2} \mathrm{O}_{3}$ is formed during oxidation of $\mathrm{TiAl}$, this phase is dispersed in the inner layer. Due to high affinity of titanium for oxygen, the dense and continuous $\mathrm{Al}_{2} \mathrm{O}_{3}$ layer cannot be formed on TiAl alloy [49]. A TiN phase, which is usually formed between the oxide scale and TiAl substrate after oxidation in air [50], may also be present in the present oxidized specimen, but this phase has not been detected by the present analytical techniques.

\subsection{Oxidation of Al-21 at\% $\mathrm{Nb}-10$ at\% Cr deposited on quartz substrate}

In order to elucidate the high oxidation resistance of the sputter-deposited Al-Nb-Cr alloy, this alloy specimen deposited on quartz substrate has been oxidized in air at $900^{\circ} \mathrm{C}$. A scanning electron micrograph of a fracture cross-section of the specimen oxidized for $24 \mathrm{~h}$ is revealed in Fig. 3. On alloy substrate with grain sizes of $\sim 100 \mathrm{~nm}$, a thin and dense oxide scale, $1 \mu \mathrm{m}$ thick, is developed. Further, whisker-like oxides are formed at the oxide surface. The formation of the whisker-like oxides is a subject of future studies. The thickness of the scale is less than one tenth of that formed on the TiAl (Fig. 1), indicating the highly protective nature of the scale formed on the Al-Nb-Cr alloy.

The X-ray diffraction pattern of the as-deposited Al-21 at\% Nb-10 at\% Cr alloy reveals only a diffuse halo, typical of amorphous structure (Fig. 4). During oxidation at $900^{\circ} \mathrm{C}$, the alloy crystallized to form an $\mathrm{Al}_{3} \mathrm{Nb}$ intermetallic phase. According to an equilibrium phase diagram for the Al-Nb-Cr ternary system [51], it is likely that a bcc chromium phase 
containing aluminum is also present due to limited solubility of chromium to the $\mathrm{Al}_{3} \mathrm{Nb}$ phase. However, such phase is not identified from the X-ray diffraction pattern shown in Fig. 4, possibly due to a low amount of the phase formed. The oxide phase identified in the oxidized specimen is only $\alpha-\mathrm{Al}_{2} \mathrm{O}_{3}$. Preferential oxidation of aluminum results in the formation of a highly protective oxide scale.

\subsection{Multilayer coatings on TiAl}

The oxidation-resistant Al-Nb-Cr alloy has been coated on to TiAl substrate. Further, anodic alumina layer has been introduced as diffusion barrier for titanium between the alloy coating and TiAl substrate. The anodic alumina has been formed by anodizing of sputter-deposited aluminum layer, $300 \mathrm{~nm}$ thick, in dilute ammonium pentaborate electrolyte. The influence of the thickness of the anodic alumina layer on the oxidation and titanium diffusion has been examined. Fig. 5 shows scanning electron micrographs and corresponding titanium X-ray image of the three-different coating specimens after oxidation at $900^{\circ} \mathrm{C}$ for 168 h: Al-Nb-Cr / TiAl (Coat-1), Al-Nb-Cr / $\mathrm{Al}_{2} \mathrm{O}_{3}(470 \mathrm{~nm}) /(\mathrm{Ti}-\mathrm{Al}) \mathrm{Ox}(20 \mathrm{~nm}) / \mathrm{TiAl}$ (Coat-2) and $\mathrm{Al}-\mathrm{Nb}-\mathrm{Cr} / \mathrm{Al}_{2} \mathrm{O}_{3}(300 \mathrm{~nm}) / \mathrm{Al}(110 \mathrm{~nm}) / \mathrm{TiAl}$ (Coat-3). Besides whisker-like oxides formed for the Coat-3 specimen, thin oxide scales of less than $2 \mu \mathrm{m}$ thickness are formed on all the coated Al-Nb-Cr alloy layers. The scales consisted mainly of aluminum oxide. Formation of the rather thin oxide scales implies that the all coatings effectively suppress the oxidation of TiAl at $900^{\circ} \mathrm{C}$ for $168 \mathrm{~h}$. From Figs. 5(a-b), however, the diffusion of titanium is obvious from the TiAl substrate to the Al-Nb-Cr alloy layer. Incorporation of titanium into the alloy coating may deteriorate its high oxidation resistance after further prolonged oxidation. Introduction of anodic alumina layers suppresses effectively the diffusion of titanium into the coatings as shown in Figs. 5(c-f). The Coat-3 appears to suppress the diffusion more effectively than the Coat-2. In the Coat-3 un-anodized thin 
aluminum layer is present beneath the anodic alumina layer, while a part of TiAl substrate is also anodized in the Coat-2. Absence of titanium species in anodic layer should be preferable to avoid titanium diffusion to the alloy coating.

Fig. 6 shows field emission scanning electron micrographs of the Coat-2 specimen after oxidation for $168 \mathrm{~h}$. The thin anodic alumina layer, less than $500 \mathrm{~nm}$ thick, is present beneath the Al-Nb-Cr alloy layer. The anodic alumina, which is amorphous before exposing at the high temperature environment, appears to crystallize and its grain size is similar to the layer thickness. More continuous anodic alumina layer with apparently smaller grain size is seen for the Coat-3 specimen (Fig. 7). Further, the TiAl substrate immediately beneath the anodic alumina layer has fine grained and porous morphology, possibly associated with the presence of a thin metallic aluminum layer before oxidation at high temperature. During heating, the aluminum layer should melt and react with the underlying TiAl substrate, resulting in the change in the morphology of the substrate. However, the anodic alumina layer is still present as a continuous layer, acting as barrier for titanium diffusion.

Although diffusion of titanium is effectively suppressed for the Coat-3 specimen, many micro-cracks are generated in the Al-Nb-Cr alloy coating. And oxidation of the TiAl substrate occurs through the micro-cracks, resulting in the formation of $\mathrm{TiO}_{2}$ (Fig. 8). Micro-cracks were also found for the Coat-2 specimen, but most of the cracked regions were healed by filling the cracks with the oxidation products of the Al-Nb-Cr alloy. The severe cracking for the Coat-3 specimen may, therefore, be associated with an aluminum layer, with a low melting point, present beneath the anodic alumina layer.

The oxidation of the TiAl substrate through microcracks of the coatings has been successfully suppressed by a pre-oxidation treatment at lower temperature. The pre-oxidation treatment was carried out in air at $800^{\circ} \mathrm{C}$ for 24 h. Fig. 9 shows scanning electron micrograph and X-ray images for the surface of the Al-Nb-Cr / $\mathrm{Al}_{2} \mathrm{O}_{3}(360 \mathrm{~nm}) / \mathrm{Al}(90 \mathrm{~nm}) / \mathrm{TiAl}$ 
specimen pre-treated and subsequently oxidized at $900^{\circ} \mathrm{C}$ for $168 \mathrm{~h}$. Micro-cracks are still present in the coating, but the cracked regions are well healed and no titanium is detected on the surface. In this manner, by applying pre-oxidation treatment, the TiAl substrate is protected against oxidation at high temperatures by the present multi-layer coatings, which comprise Al-Nb-Cr alloy / anodic $\mathrm{Al}_{2} \mathrm{O}_{3}$ / Al layers. Since diffusion of titanium to the coating is suppressed, it is likely that this coating protects the TiAl substrate even after prolonged oxidation.

This type of multi-layer coatings is probably applied to a range of metallic materials for protection against high temperature oxidation. It should be mentioned that the oxidation-resistant Al-Nb-Cr alloy layer can be replaced by other oxidation-resistant materials, such as nickel aluminides, silicon carbides and Ni-base superalloys. In the present study, the aluminum layer was prepared by sputter deposition, which may not be suitable for practical application for the deposition on substrates with complex shapes. Other techniques, including electrodeposition from molten salts, should be preferable for the deposition of aluminum layer.

\section{Conclusions}

Multilayer coatings, comprising an outer oxidation-resistant Al-Nb-Cr alloy layer and an inner anodic $\mathrm{Al}_{2} \mathrm{O}_{3}$ layer acting as diffusion barrier, have been applied to protect $\gamma$-TiAl substrate against high temperature oxidation. During oxidation in air at $900^{\circ} \mathrm{C}$ diffusion of titanium occurs from TiAl substrate to the alloy coating when the Al-Nb-Cr alloy is coated directly on the substrate. The anodic $\mathrm{Al}_{2} \mathrm{O}_{3}$ layer, less than $500 \mathrm{~nm}$ thick, formed by anodizing of a sputter-deposited aluminum layer, suppresses the diffusion effectively, particularly when a thin aluminum layer is remained beneath the anodic film. Micro-cracks are formed in the coating, at which $\mathrm{TiO}_{2}$ is formed by oxidation of the $\mathrm{TiAl}$ substrate. The oxidation of the TiAl 
substrate through the cracks can be avoided by a pre-oxidation treatment at lower temperature of $800^{\circ} \mathrm{C}$.

\section{Acknowledgments}

The present work was supported in part by the Light Metal Educational Foundation, Inc.

\section{References}

[1] D.M. Dimiduk, Mater. Sci. Eng., A263 (1999) 281.

[2] E.A. Loria, Intermetallics, 8 (2000) 1339.

[3] T. Tetsui, Current Opinion in Solid State \& Mater. Sci., 4 (1999) 243.

[4] J.W. Fergus, Mater. Sci. Eng., A338 (2002) 108.

[5] E. Kobayashi, M. Yoshihara, R. Tanaka, J. Jpn. Inst. Met., 53 (1989) 251.

[6] S. Taniguchi, T. Shibata, A. Murakami, K. Chihara, Oxid. Met., 42 (1994) 17.

[7] S. Taniguchi, T. Shibata, S. Sakon, Mater. Sci. Eng., A198 (1995) 85.

[8] S. Kim, D. Lee, I. Kim, Mater. Sci. Tech., 15 (1999) 575.

[9] T. Narita, T. Izumi, M. Yatagai, T. Yoshioka, Intermetallics, 8 (2000) 371.

[10] T. Izumi, T. Yoshioka, S. Hayashi, T. Narita, Intermetallics, 9 (2001) 547.

[11] Z.D. Xiang, S.R. Rose, P.K. Datta, Mater. Sci. Tech., 19 (2003) 1247.

[12] T. Izumi, T. Nishimoto, T. Narita, Intermetallics, 11 (2003) 841.

[13] Z.D. Xiang, S.R. Rose, P.K. Datta, Mater. Chem. Phys., 80 (2003) 482.

[14] Z.D. Xiang, S.R. Rose, P.K. Datta, Surf. Eng., 18 (2002) 373.

[15] T. Nishimoto, T. Izumi, S. Hayashi, T. Narita, Intermetallics, 11 (2003) 225.

[16] Z.D. Xiang, S.R. Rose, P.K. Datta, Mater. Sci. Tech., 18 (2002) 1479.

[17] C.G. Zhou, H.B. Xu, S.K. Gong, K.Y. Kim, Mater. Sci. Eng., A341 (2003) 169.

[18] Z.D. Xiang, S. Rose, P.K. Datta, Surf. Coat. Tech., 161 (2002) 286. 
[19] C.G. Zhou, H.B. Xu, S.K. Gong, Y. Yang, K.Y. Kim, Surf. Coat. Tech., 132 (2000) 117.

[20] S. Kim, D. Park, I. Kim, H. Kim, K. Park, Mater. Sci. Tech., 14 (1998) 822.

[21] T.C. Munro, B. Gleeson, High Temperature Corrosion and Protection of Materials 4, Pts 1 and 2. 1997, p.753.

[22] M.F. Stroosnijder, N. Zheng, W.J. Quadakkers, R. Hofman, A. Gil, F. Lanza, Oxid. Met., 46 (1996) 19.

[23] U. Hornauer, E. Richter, E. Wieser, W. Moller, A. Donchev, M. Schutze, Surf. Coat. Tech., 174 (2003) 1182.

[24] M. Yoshihara, S. Taniguchi, Y.C. Zhu, Met. Mater. Trans., 34A (2003) 2253.

[25] Y.C. Zhu, X.Y. Li, K. Fujita, N. Iwamoto, Y. Matsunaga, K. Nakagawa, S. Taniguchi, Surf. Coat. Tech., 158 (2002) 503.

[26] M.K. Lei, X.P. Zhu, X.J. Wang, Oxid. Met., 58 (2002) 361.

[27] S. Taniguchi, Y.C. Zhu, K. Fujita, N. Iwamoto, Oxid. Met., 58 (2002) 375.

[28] M. Yoshihara, S. Taniguchi, Y.C. Zhu, High Temperature Corrosion and Protection of Materials 5, Pts 1 and 2, 2001. p.395.

[29] Y.C. Zhu, Y. Zhang, X.Y. Li, K. Fujita, N. Iwamoto, Oxid. Met., 55 (2001) 119.

[30] X.Y. Li, Y.C. Zhu, K. Fujita, N. Iwamoto, Y. Matsunaga, K. Nakagawa, S. Taniguchi, Mater. Trans. JIM, 41 (2000) 1157.

[31] U. Hornauer, E. Richter, W. Matz, H. Reuther, A. Mucklich, E. Wieser, W. Moller, G. Schumacher, M. Schutze, Surf. Coat. Tech., 128 (2000) 418.

[32] Y.C. Zhu, Y. Matsumoto, K. Fujita, N. Iwamoto, Mater. Trans. JIM, 41 (2000) 574.

[33] U. Hornauer, R. Gunzel, H. Reuther, E. Richter, E. Wieser, W. Moller, G. Schumacher, F. Dettenwanger, M. Schutze, Surf. Coat. Tech., 125 (2000) 89.

[34] S. Taniguchi, K. Uesaki, Y.C. Zhu, Y. Matsumoto, T. Shibata, Mater. Sci. Eng., A266 
(1999) 267.

[35] G. Schumacher, C. Lang, M. Schutze, U. Hornauer, E. Richter, E. Wieser, W. Moller, Mater. Corros., 50 (1999) 162.

[36] U. Hornauer, E. Richter, E. Wieser, W. Moller, G. Schumacher, C. Lang, M. Schutze, Nucl. Inst. Meth. B, 148 (1999) 858.

[37] S. Taniguchi, K. Uesaki, Y.C. Zhu, H.X. Zhang, T. Shibata, Mater. Sci. Eng., A249 (1998) 223.

[38] V.A.C. Haanappel, M.F. Stroosnijder, Surf. Coat. Tech., 105 (1998) 147.

[39] S. Taniguchi, T. Shibata, T. Saeki, H.X. Zhang, X.H. Liu, Mater. Trans. JIM, 37 (1996) 998.

[40] J.K. Lee, M.H. Oh, D.M. Wee, Intermetallics, 10 (2002) 347.

[41] Y. Iino, K. Yaesawa, Int. J. Modern Phys. B, 17 (2003) 1158.

[42] C.L. Zheng, Z. Xu, X.S. Xie, Z.Y. He, J.X. Dong, M.C. Zhang, Rare Met. Mater. Eng., $32(2003) 32$.

[43] C. Leyens, M. Peters, P.E. Hovsepian, D.B. Lewis, Q. Luo, W.D. Munz, Surf. Coat. Tech., 155 (2002) 103.

[44] L. Young, Anodic oxide films, London, Academic Press, 1961.

[45] G.C. Wood, P. Skeldon, G.E. Thompson, K. Skeldon, J. Electrochem.Soc., 143 (1996) 74.

[46] P. Skeldon, K. Shimizu, G.E. Thompson, G.C. Wood, Surf. Interface Anal., 5 (1983) 252.

[47] A.C. Harkness, L. Young, Can. J. Chem., 44 (1966) 2409.

[48] J.P.S. Pringle, Electrochim. Acta, 25 (1980) 1420.

[49] A. Rahmel, W.J. Quadakkers, M. Schutze, Mater. Corros., 46 (1995) 271.

[50] J.D. Sunderkötter, H.J. Schmutzler, V.A.C. Haanappel, R. Hofman, W. Glatz, H. 
Clemens, M.F. Stroosnijder. Intermetallics, 5 (1997) 525.

[51] P. Villars, A. Prince, H. Okamoto, Handbook of ternary alloy phase diagrams, Materials Park, OH, ASM International, 1995. 
Figure captions

Fig. 1 Field-emission scanning electron micrograph of a fractured cross-section for the $\gamma$-TiAl alloy oxidized in air at $900^{\circ} \mathrm{C}$ for $24 \mathrm{~h}$.

Fig. 2 Grazing incidence X-ray diffraction patterns, obtained at incident angles of X-ray of 2 and $10^{\circ}$, for the $\gamma$-TiAl alloy oxidized in air at $900^{\circ} \mathrm{C}$ for $24 \mathrm{~h}$.

Fig. 3 Field-emission scanning electron micrograph of a fractured cross-section for the Al-21 at\% Nb-10 at\% Cr alloy sputter-deposited on quartz substrate after oxidation in air at $900^{\circ} \mathrm{C}$ for $24 \mathrm{~h}$.

Fig. 4 Grazing incidence X-ray diffraction patterns, obtained at incident angles of X-ray of $2^{\circ}$, for the $\mathrm{Al}-21 \mathrm{at} \% \mathrm{Nb}-10$ at\% Cr alloy sputter-deposited on quartz substrate before and after oxidation in air at $900^{\circ} \mathrm{C}$ for $24 \mathrm{~h}$.

Fig. 5 Cross-sectional SEI and X-ray images of titanium for the Coat-1, Coat-2 and Coat-3 specimens after oxidation in air at $900^{\circ} \mathrm{C}$ for $168 \mathrm{~h}$.

Fig. 6 Field emission scanning electron micrograph of a fractured cross-section for the Coat-2 specimen after oxidation in air at $900^{\circ} \mathrm{C}$ for $168 \mathrm{~h}$.

Fig. 7 Field emission scanning electron micrograph of a fractured cross-section for the Coat-3 specimen after oxidation in air at $900^{\circ} \mathrm{C}$ for $168 \mathrm{~h}$.

Fig. 8 SEI (a) and X-ray images of aluminum (b), titanium (c) and niobium (d) for the Coat-3 specimen after oxidation in air at $900^{\circ} \mathrm{C}$ for $168 \mathrm{~h}$.

Fig. 9 SEI (a) and X-ray images of aluminum (b), titanium (c) and niobium (d) for the pre-oxidized Al-Nb-Cr / $\mathrm{Al}_{2} \mathrm{O}_{3}(360 \mathrm{~nm}) / \mathrm{Al}(90 \mathrm{~nm})$ / TiAl specimen after oxidation in air at $900^{\circ} \mathrm{C}$ for $168 \mathrm{~h}$. 


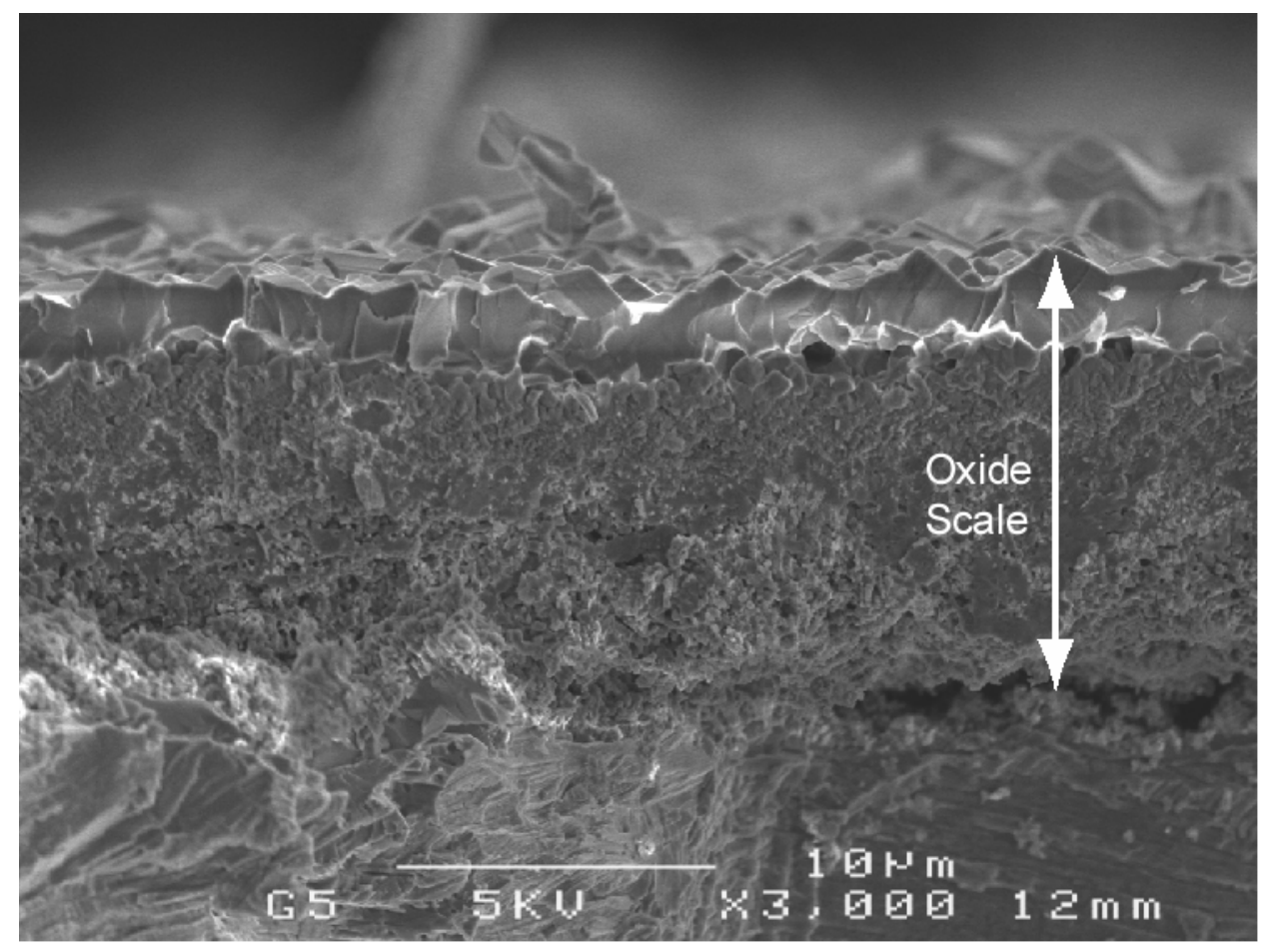

Fig. 1 


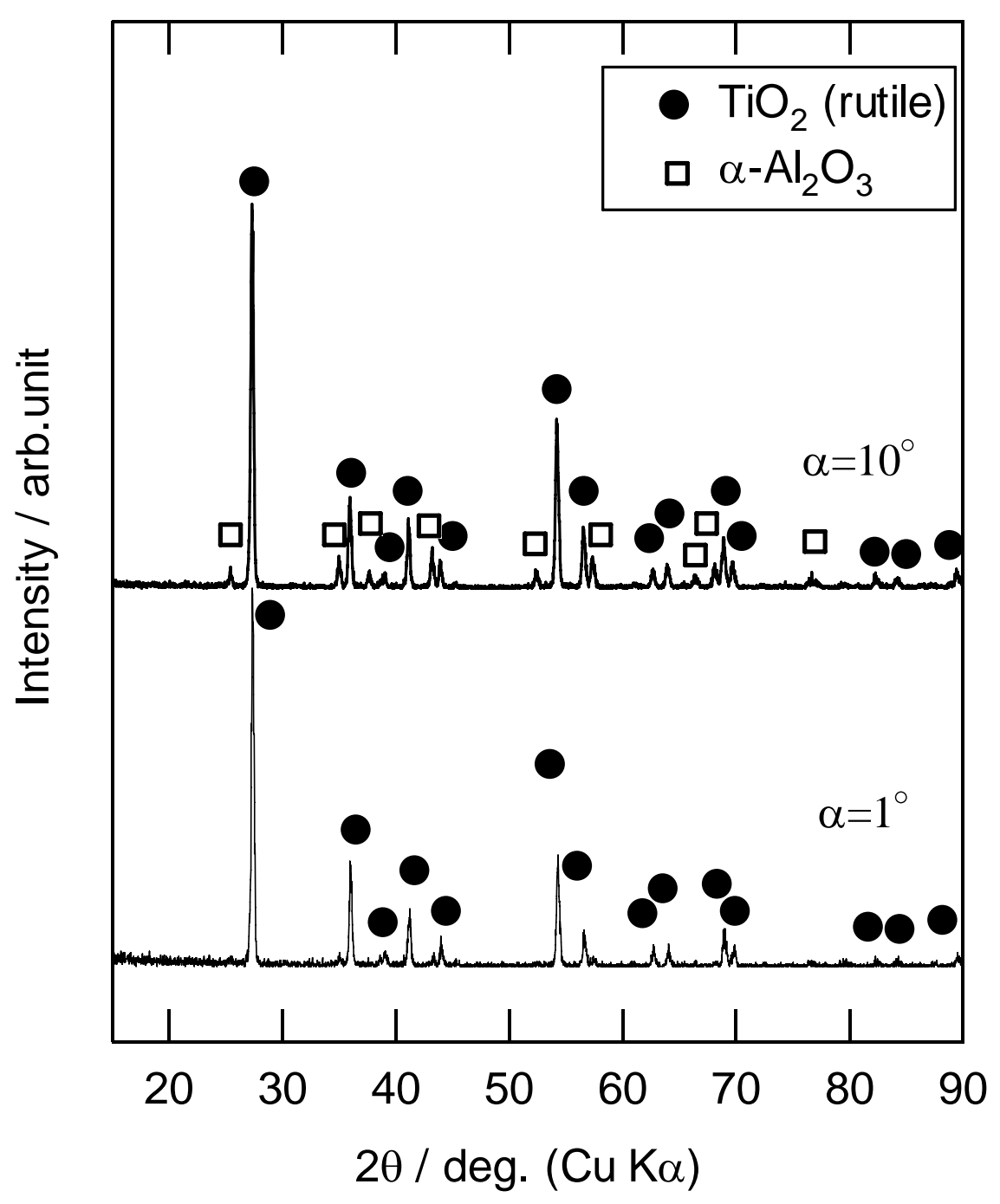

Fig. 2 


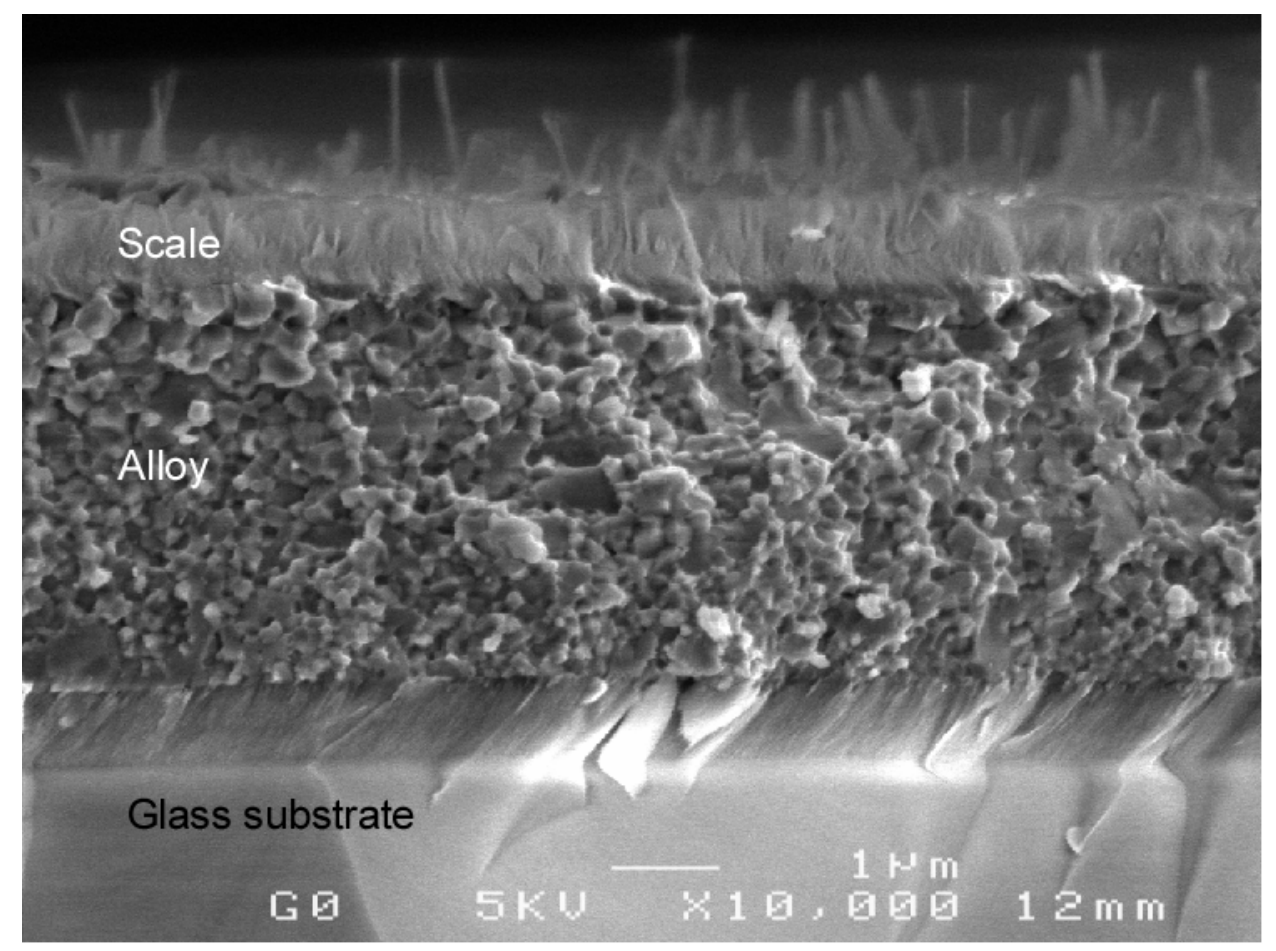

Fig. 3 


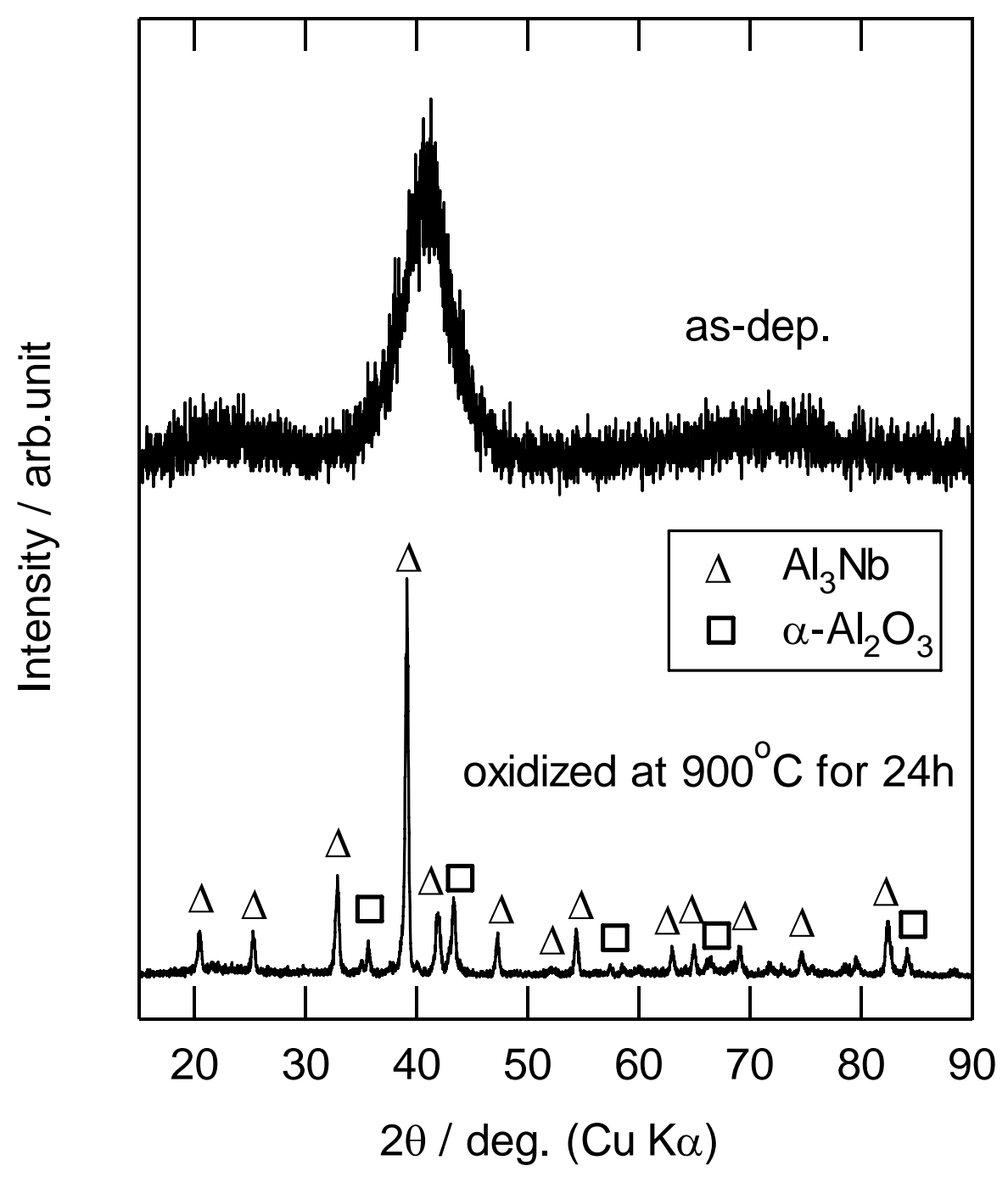

Fig. 4 

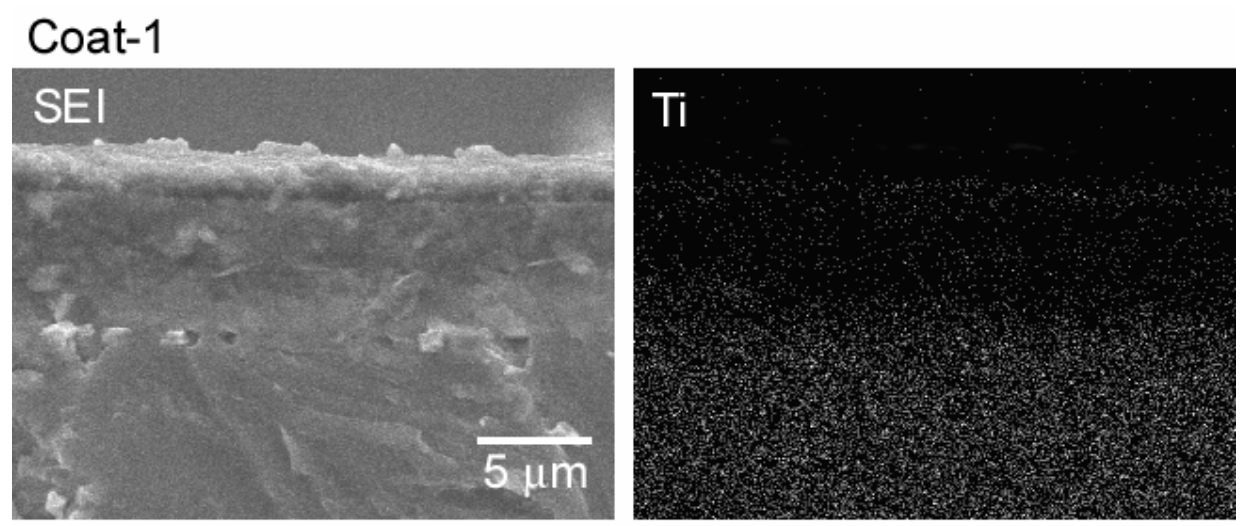

\section{Coat-2}
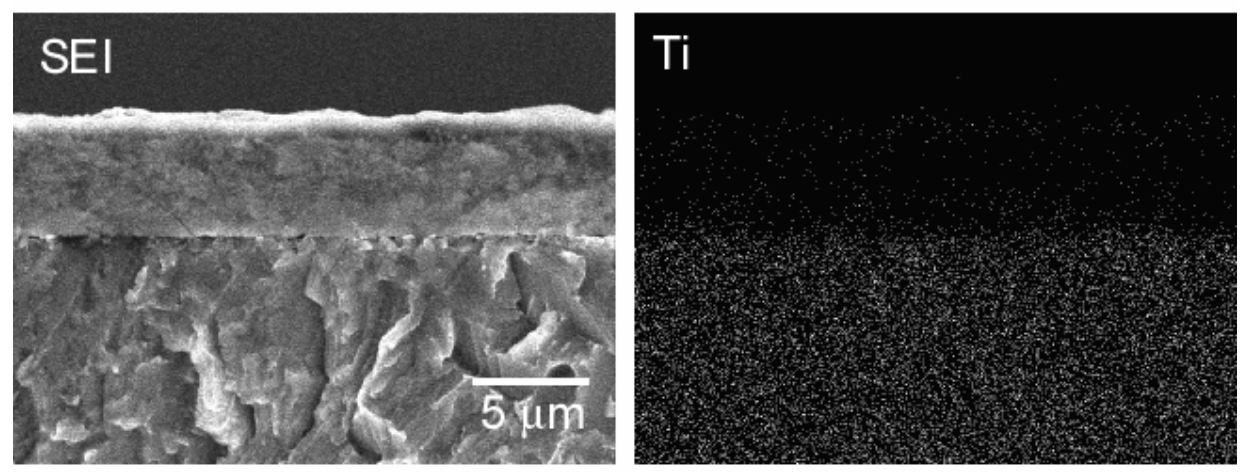

\section{Coat-3}
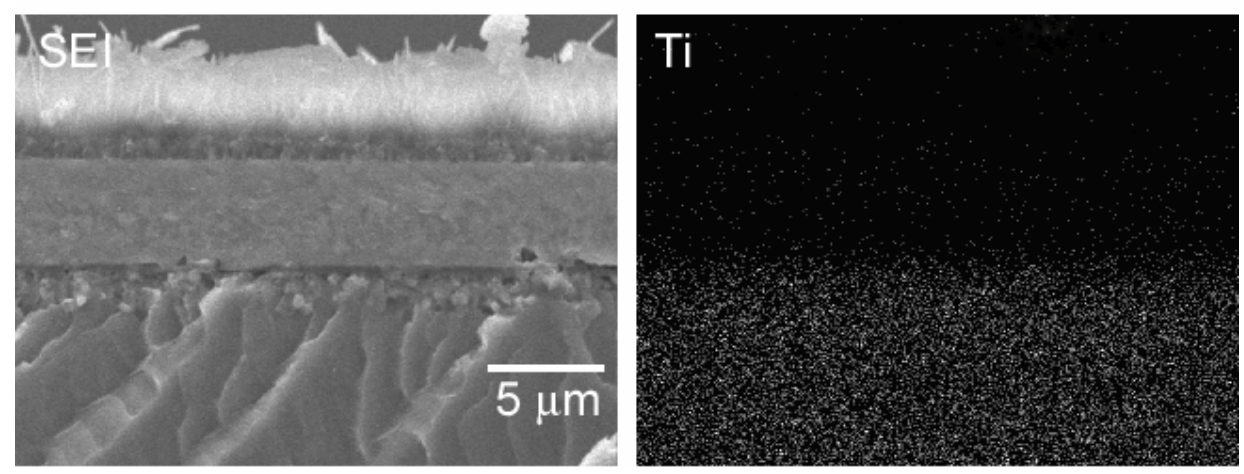

Fig.5 


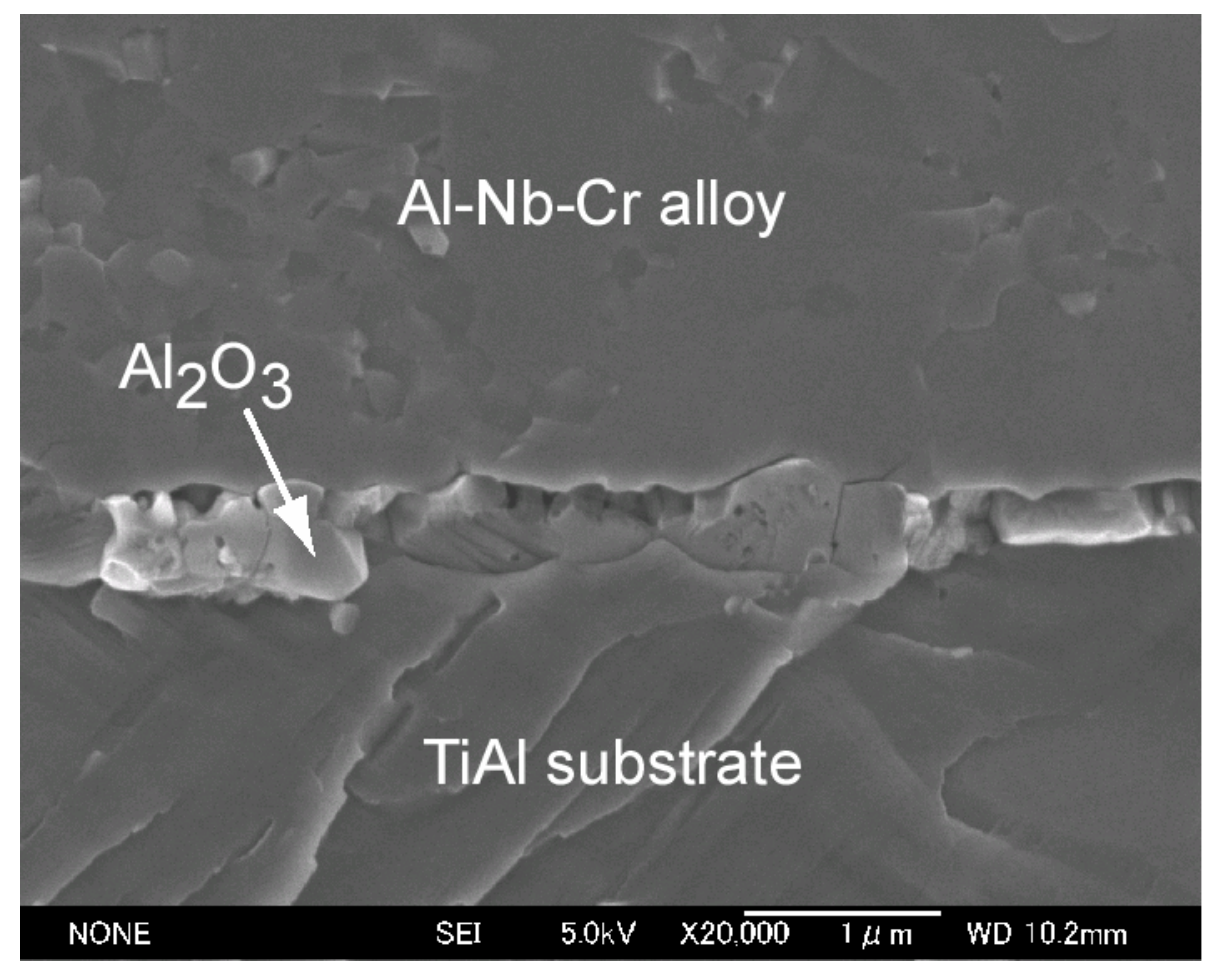

Fig. 6 


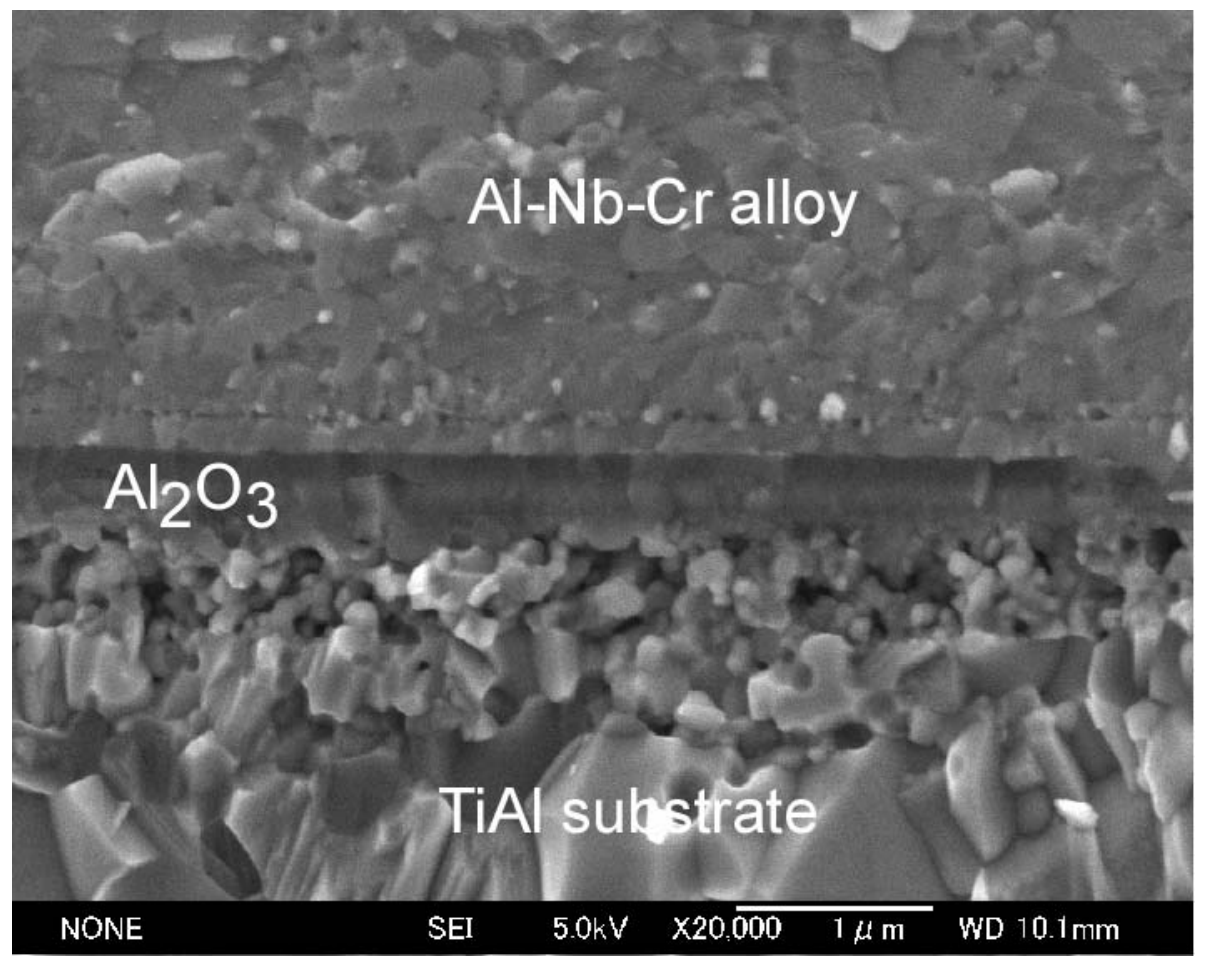

Fig. 7 
(a)

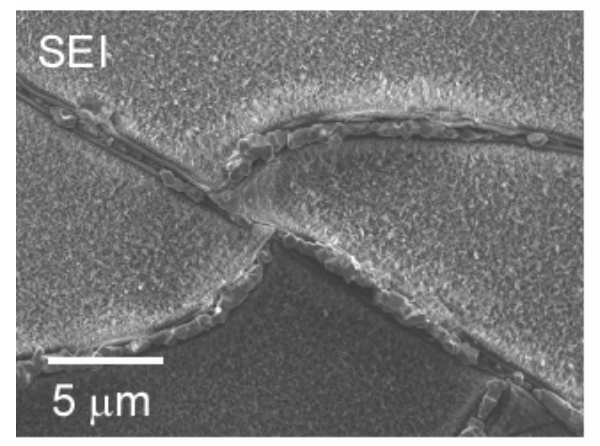

(c)

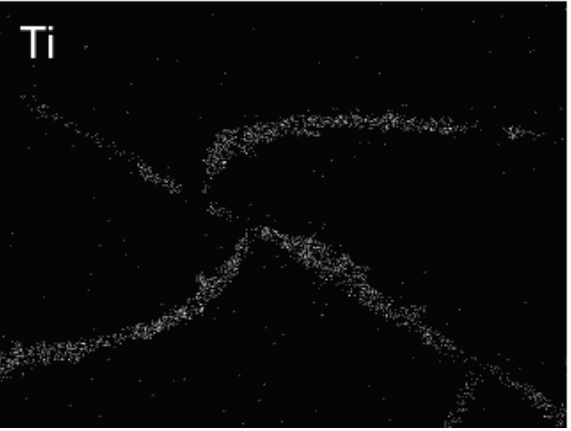

(b)

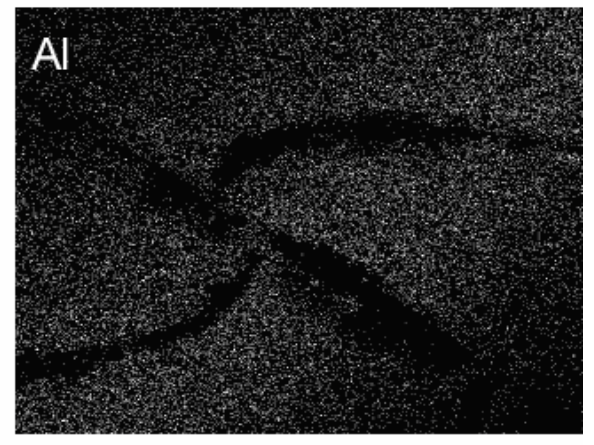

(d)

$\mathrm{Nb}$

Fig. 8 
(a)

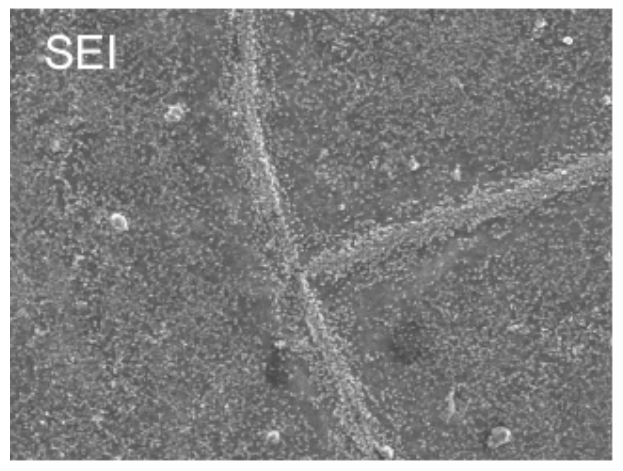

(c) (b)

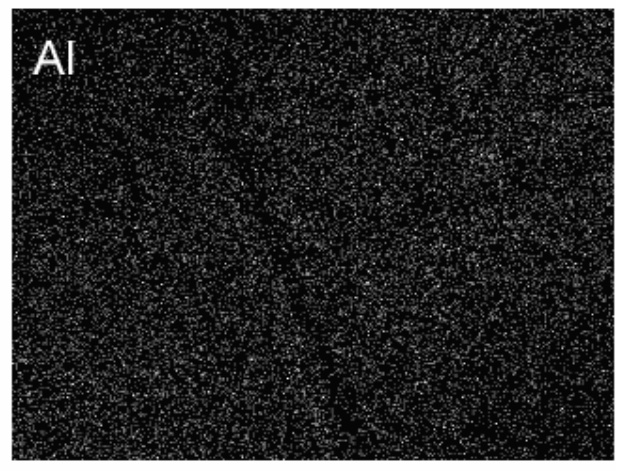

(d)

Fig. 9 